\title{
Correspondence
}

\section{Cost of a Facelift}

Str,-The issue of Nature of April 25 contains an articlo about the delay in the resurfacing of the Arecibo reflector which is misleading (Nature, 226, 308; 1970).

The eosts of the resurfacing project are neither very uncertain nor have they suddenly risen greatly. The estimated cost has increased in a year from $\$ 3.8$ million to $\$ 4 \cdot 2$ million, giving a percentage increase less than most estimates of the annual inflation in construction costs of this type. The firmness of the $\$ 4.2$ million figure is supported by a formal fixed prico bid at this figure from a competent company.

No significant engineering problems have been uncovered. There is no serious eriticism of the proposed type of surface panel and no indication that a heavier surface would be necessary. The engineering of new surface on a foundation whose accuracy is already known is quite straightforward, and the major challenge is actually in determining the least expensive mode of fabrication of the largo number of panels.

There is thus no reason for thinking that a much higher price estimate at some future time will arise and that this will require a re-evaluation of radio astronomy priorities. The resurfacing of the Arecibo reflector remains scientifically the most exciting and cost-effective foreseeable improvement to the world's astronomy oquipment, and is one of the most promising projects of science in general.

\section{Sincerely yours,}

\section{Frank D. Drake}

Cornell University,

Arecibo Project Office,

Space Seiences Building,

Ithaca, NY 14850, USA.

It is good to have Professor Drake's assurance, but it remains a fact that the National Science Foundation has undertaken to the Authorization Committee in the Senate that it will not expect to be awarded the money asked for on behalf of Arecibo until a further engineering study has been carried out. Everybody will hope that Professor Drake is right and he after all should know-he has done the work.-Editor, Nature.

\section{Abortion Act in Action}

SIR,-Your note on the Abortion Act (Nature, 225, 580; 1970) quotes an estimate ${ }^{1}$ of 18,000 private legal abortions in 1967 , in addition to 10,000 under the National Health Service. Reliable figures for private terminations before the Abortion Act are certainly hard to come by, but there is unequivocal proof that this estimate must bo exaggerated.

In $1967,9,700$ (not 10,000$)$ NHS abortions were officially reported for England and Wales ${ }^{2}$, so that another 18,000 privately procured would make a total of 27,700 pregnancies legally terminated in that year. But in the first 9.5 weeks under the now Act (April 27-July 2, 1968) $2,752 \mathrm{NHS}$ and 1,660 private legal abortions were notified, corresponding to an annual rate of 24,036 . Since it is not to be believed that the coming into operation of a new and more permissive law should have resulted in a significant reduction of the legal abortion rate, and since the NHS total is well established, it is the estimate for private abortions in 1967 which must be too high. Q.E.D.

If the 1967 rate had been the same as for the 9 weeks after April 27, 1968, there would have been no more than 14,356 private legal abortions in that year. But this also soems too high, and it is unlikely that the true figure could have exceeded 10,000 , to give a total of 19,700 legal abortions in 1967. This would imply that the 1967 rate had boen 18 per cent below what it was immediately after the new Act came into force, which is not excessive when compared with the 32 per cent increase in the next quarter (7,938 in the 13 weeks July 3 -October 1), and a further 25 per cent $(9,907$ legal abortions) for the quarter ended December $31,1968^{3}$.

Your note also says that while there had been betwoen 45 and 50 deaths from abortion each year for the past 20 or so years, this had dropped to 22 during 1969 . But that is not so, since the figure of 22 was only for the 10 months ended October 31,19694. Mr Richard Crossman (Minister of State for the Social Services) has recently given $^{5}$ the provisional total for the full year 1969 as 29 deaths due directly to abortion, including 4 resulting from legally induced abortion (ICD 640 and 641), but not including a further 13 deaths after legal terminations of pregnancy under the Act which were not classified as directly due to abortion.

It may well be true that abortion dcaths have averaged 45-50 over the past 20 years, but the rate is known to have been falling during this period, and for 1967, which was the last full year under the old law, the Registrar General ${ }^{3}$ recorded 34 abortion deaths:

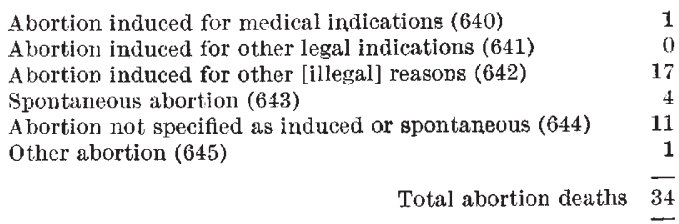

Even assuming that none of the 13 deaths following upon but not classified as directly due to legal abortions in 1969 would formerly have been counted as abortion deaths, and it is not entirely clear whethor this would have been so, the improvement has been only from 34 deaths in 1967 to 29 in 1969. Perhaps 1967 may have been a better year than average, but your note in concluding that "The Act has been remarkably successful in reducing the death rate from abortion. The latest figures from the Ministry of Health show that in England and Wales the number of deaths from abortion, which has been between 45 and 50 per year for the past twenty or so years, dropped to 22 during $1969^{\prime \prime}$, docs perhaps rather overstate the case.

Yours etc.,

\section{B. GoOdHaRT}

Gonville and Caius College,

Cambridgo.

1 Diggory, P., Peel, J., and Polts, M., Lancet, i, 287 (1970).

2 Crossman, R.,Hansard (Commons), written answers, col. I5 (Nov, 10, 1969).

$s$ Registrar General, Quarterly Returns for England and Wales (1968-69).

- Crossman, R., Hansard (Commons), written answers, col. 197 (Feb, 5,1970 ).

${ }^{6}$ Crossman, R., Hansard (Commons), written answers, col, 272 (Mar. $23,1970)$. 